\title{
Victor Bérard et la Macédoine
}

\section{Ivan Savev}

\section{(2) OpenEdition}

Journals

Édition électronique

URL : https://journals.openedition.org/ceb/819

DOI : $10.4000 /$ ceb.819

ISSN : 2261-4184

Éditeur

INALCO

\section{Édition imprimée}

Date de publication : 30 mars 2011

Pagination : 149-166

ISBN : 978-2-85831-189-7

ISSN : 0290-7402

\section{Référence électronique}

Ivan Savev, «Victor Bérard et la Macédoine », Cahiers balkaniques [En ligne], 38-39 | 2011, mis en ligne le 05 janvier 2011, consulté le 06 juillet 2021. URL : http://journals.openedition.org/ceb/819 ; DOI : https://doi.org/10.4000/ceb.819

Ce document a été généré automatiquement le 6 juillet 2021.

\section{(c) (†) 8)}

Cahiers balkaniques est mis à disposition selon les termes de la Licence Creative Commons Attribution - Pas d'Utilisation Commerciale 4.0 International. 


\title{
Victor Bérard et la Macédoine
}

\author{
Ivan Savev
}

1 Victor Bérard fut un érudit polyvalent, historien, archéologue, géographe, analyste des affaires internationales et homme politique (il a même été sénateur). Avec sa double compétence de spécialiste de l'histoire de la région sud balkanique et de géopoliticien avant la lettre, il a analysé la situation complexe et l'enchevêtrement des forces internes ainsi que les ingérences des puissances dans les affaires macédoniennes. Sa contribution, par ses enquêtes et ses témoignages, est essentielle pour la connaissance de la géopolitique sud balkanique de la fin du XIX et du début du XX ${ }^{e}$ siècle, et surtout du processus de partage de la Macédoine.

2 À cette époque plusieurs intellectuels européens ont participé à la polémique sur « la question d'Orient » dont faisait partie la Macédoine, et proposé leurs solutions pour son avenir. Victor Bérard décida d'étudier les problèmes de la Macédoine ottomane sur place. Il commença ses enquêtes en octobre 1896. En tant que membre de l'École d'Athènes, il fit des fouilles archéologiques sur des sites de la Grèce antique et visita la Macédoine et l'Albanie ${ }^{1}$. Son premier contact avec la réalité macédonienne date de 1890.

3 Victor Bérard est né à Morez dans le Jura en 1864. Sorti de l'École Normale Supérieure à Paris, il est agrégé d'histoire en 1887, puis nommé à l'École française d'Athènes. Dans sa thèse sur l'Origine des cultes arcadiens en 1894, il place la Phénicie à la base de la mythologie du Péloponnèse. Après les Phéniciens, il passe à l'étude de l'Odyssée d'Homère et jusqu'à la fin de sa vie en 1931, à Paris, il reprendra plusieurs fois le sujet de l'Odyssée et des navigations d'Ulysse.

\section{La Macédoine dans le contexte géopolitique avant les enquêtes de Victor Bérard}

4 Depuis le début de la conquête turque au $\mathrm{XV}^{\mathrm{e}}$ siècle la Macédoine vivait sous la double autorité $\mathrm{du}$ sultan et du Patriarche œcuménique, en réalité, grec. C'était la configuration politico-religieuse byzantine que les Turcs avaient adoptée, eux aussi. 
5 En 1454, le sultan Mehmed II, se considérant comme le successeur des empereurs de l'Empire romain d'Orient, a intronisé le patriarche grec qui, en retour, l'assura de sa loyauté et le reconnut comme successeur légitime du dernier Basileus ${ }^{2}$. Cette information contient toute l'ambiguïté qui s'établit alors dans les rapports entre les Grecs, les Turcs et les autres peuples des Balkans. Selon l'organisation de la société ottomane, les Turcs reconnaissaient deux principales «nations religieuses» ( millets ») dans les Balkans, les Musulmans et les Orthodoxes. Ces derniers étaient appelés aussi «Rums » ou parfois, «Grecs » sans distinction d'appartenance ethnique ou de langue. Par la suite, en 1870, sous la pression des Russes, les Turcs ont créé l'Exarchat bulgare qui regroupait une grande partie des orthodoxes slavophones. On les a appelés « Exarchistes » ou « Bulgares », à l'exception des Serbes qui restèrent fidèles au Patriarche grec. Cette division de la "nation religieuse orthodoxe " ou " grecque » en «patriarchistes » et « exarchistes », préfigura le partage de la Macédoine selon des critères linguistiques.

6 Pendant quatre siècles la population de la Turquie d'Europe, en fait la péninsule balkanique, a vécu sous la chape de plomb turque, isolée du reste de l'Europe.

$7 \mathrm{Au} \mathrm{XIX}$ siècle, quand la colonisation de la planète par l'Occident a atteint son apogée, les grandes puissances ont commencé à montrer de l'intérêt aussi pour les Balkans. En arrachant des territoires aux Turcs, elles ont créé, à partir de 1830, des protectorats autour de la Macédoine : le Royaume de la Grèce en 1830, les royaumes de Serbie et de la Roumanie, au Congrès de Berlin en 1878, ainsi que la Principauté autonome de Bulgarie. À cette occasion, on créa aussi, au sud de la Bulgarie, une province autonome, toujours ottomane, mais dirigée par un gouverneur chrétien, la Roumélie orientale. Quant à la Macédoine, le Congrès de Berlin décida de la laisser aux mains des Turcs. L'article $23 \mathrm{du}$ traité prévoyait des réformes que le sultan devait entreprendre pour améliorer les conditions de vie des populations, mais elles n'ont jamais été réalisées.

8 Le Royaume-Uni était alors, la première puissance coloniale du monde, suivi par la France du Second Empire et de la Troisième République. Mais, paradoxalement, pendant que les puissances se partageaient le monde et soumettaient les peuples, dans les Balkans, elles faisaient campagne pour libérer les peuples de la domination turque. C'est l'insurrection des Grecs de Valachie en 1821 qui leur servit de prétexte pour lancer cette offensive: "C'est de la Roumanie que partit le premier essai d'émancipation de la Grèce. L'idée politique vint de Russie ", écrivit Jacques Ancel ${ }^{3}$. L'Europe devient philhellène, poussée par le romantisme: "à l'origine, écrit-il, le philhellénisme est tout littéraire. Le ton en est donné par Lord Byron... » suivi par d'autres écrivains européens «qui furent la meilleure des réclames pour la cause hellénique » et pour recueillir des fonds pour les insurgés.

9 C'est qu'à cette époque, en Occident, l'intérêt pour l'histoire de « l'Antiquité grecque » était immense. Sous ce nom de " grec ", on comprenait l'histoire ancienne des Balkans $\mathrm{du}$ Sud. Cet intérêt, d'abord littéraire et romantique, se transforma en argument historique et géopolitique, et devint la base de l'idéologie de la colonisation occidentale. Pour justifier la supériorité de leur " race blanche » dans leur œuvre de colonisation, les Occidentaux choisirent comme ancêtres les Hellènes des cités, pour la culture classique, et les Macédoniens pour leurs conquêtes du monde connu de l'Antiquité, en leur donnant le nom générique de Grecs. C'est dans ce sens que le Prussien Johann Gustav Droysen, préoccupé par les problèmes de l'unification allemande, reconstitua l'histoire de l'Antiquité sud balkanique qu'il appela plus tard 
« Histoire de l'Hellénisme ». Il y distingua d'abord la « race macédonienne nordique » et la " race méditerranéenne des Hellènes » pour ensuite confondre les deux.

Dans ses études, Victor Bérard au contraire, spécialiste de cette histoire, ne confond pas les Grecs et les Macédoniens; il se distingue sur ce point des philhellènes convaincus, pour qui il n'y avait que des Hellènes dans les Balkans du Sud et qui ont poussé les décideurs des grandes puissances à donner la priorité et des privilèges aux Grecs modernes en les reconnaissant comme les descendants directs des Hellènes.

\section{Le processus de partage de la Macédoine}

11 Après avoir créé les États sud balkaniques au Congrès de Berlin, les grandes puissances ont laissé aux mains des Turcs la Macédoine, l'Albanie et une partie de la Thrace. Puis, les deux grandes puissances les plus directement concernées conclurent un accord en 1897 sur le «statu quo » de ces territoires. «L'entente austro-russe livre la Macédoine au bon plaisir du Sultan [...] Après la révolte macédonienne de 1897, 200000 Macédoniens trouvaient refuge dans la Bulgarie [...] La Macédoine devient le champ clos des comitadjis slaves, des andartès (irréguliers) grecs et des bachi-bouzouk musulmans " précisa Jacques Ancel. Le traité de Berlin n'a pas donné entièrement satisfaction aux nouveaux États dans leurs prétentions territoriales. Il a laissé la Macédoine à l'Empire turc, signifiant ainsi qu'elle restait « un pays à prendre et à coloniser » comme l'a écrit Victor Bérard. Mécontents des décisions du Congrès, dès lors ces États voisins ont tourné leurs regards vers la Macédoine et les autres territoires restés aux mains des Turcs.

Cependant, les grandes puissances empêchèrent la Grèce de s'emparer de l'Épire tandis que les Britanniques occupaient Chypre. Les Grecs ont cependant obtenu, en 1881, la Thessalie, ce qui les conduisit aux portes de la Macédoine et dès ce moment, ils entamèrent des manœuvres diplomatiques en direction des puissances européennes et, en même temps, collaborèrent parfois avec les Turcs pour s'assurer la possession de la Macédoine. Dans le même temps, les Serbes dont l'accès à la mer Adriatique a été coupé par l'occupation autrichienne de la Bosnie-Herzégovine se sont tournés immédiatement vers la Macédoine et vers la mer Égée.

13 Les Russes ont signé un traité de paix avec la Turquie en février-mars 1878 qui leur permettait d'élargir leur zone d'influence dans les Balkans. Mais, trois mois plus tard, les puissances occidentales ont refusé le plan russe de San Stefano qui créait une grande Bulgarie englobant une grande partie de la Macédoine historique et géographique ; à Berlin, elles ont réduit les ambitions russes en limitant la Principauté autonome de Bulgarie dépendante de l'Empire turc, au territoire bulgare proprement dit, entre le Danube et les Balkans. Au sud de ce territoire, elles ont créé une Principauté de Roumélie orientale que les Bulgares ont annexée en 1885, ne respectant pas le règlement du Congrès. La Bulgarie est arrivée ainsi à la frontière orientale de la Macédoine.

14 Quant aux Albanais, Bismarck, paraît-il, avait déclaré catégoriquement: «la nation albanaise n'existe pas ». 


\section{Les arguments des différents partis} légitimes. De l'archipel aux Balkans et du Pinde à la mer Noire, leurs cartes tendancieuses annexent tout le pays. " Mais il constate que «si la côte est hellénisée, tout l'intérieur est slave ». Il se demande : «Serbe ou Bulgare? » Et il répond : «Leurs arguments suivant qu'ils sont exposés à Belgrade ou à Sofia prouvent infailliblement que toute la Macédoine est serbe ou toute la Macédoine est bulgare. En réalité, écrit-il, cette masse slave [...] varie du Bosniaque le plus pur au Bulgare authentique, en passant par le Serbe et le Macédonien proprement dit [...]. Ils se disaient Bulgares hier, ils se disent Serbes aujourd'hui, ils se diront Macédoniens demain ». (Comme il n'y avait pas de Bosniaques en Macédoine, on peut supposer qu'il appelle ainsi les Slaves islamisés).

Serbes et les Bulgares soutiennent que la langue des Macédoniens slavophones serait pour les premiers, du serbe, et du bulgare, pour les seconds. En réalité, la création de l'écriture slave a commencé par la christianisation des Slaves de Macédoine dans leur langue à partir du VII ${ }^{\mathrm{e}}$ siècle. Les adaptations de l'alphabet grec aux sons de la langue slave ont abouti à la création de l'alphabet glagolitique par Cyrille et Méthode et à leur traduction des livres d'église du grec en langue des Slaves installés aux environs de Salonique. Le fait est que les États bulgare et serbe ont occupé la Macédoine un certain temps au Moyen Âge et ils en tirent des droits historiques. Mais leurs arguments étant presque identiques, leurs revendications s'annulent mutuellement.

En ce qui concerne les revendications des Grecs, ils n'ont jamais, comme État, occupé la Macédoine avant 1912, puisque c'est seulement, en 1830, qu'ils ont eu leur premier État. Leur argument était linguistique et s'appuyait sur l'Antiquité : la chancellerie du Royaume de Macédoine utilisait le grec attique et l'aristocratie macédonienne était bilingue, mais le peuple était «barbare » parce qu'il ne parlait pas le grec. Cependant, en 1913, c'est justement sur la base de cet argument fallacieux que les puissances ont attribué aux Grecs modernes la moitié de la Macédoine antique.

\section{Les analyses de la question macédonienne}

Victor Bérard, helléniste et spécialiste d'Homère, se consacre à l'étude de la situation ethnique et politique en Macédoine ottomane à partir de1890. Il fait des fouilles archéologiques en Grèce et, visitant la Macédoine en 1890, il s'intéresse à ses problèmes intérieurs et aux conditions de vie de la population.

Il a alors l'impression qu'« un semblant d'équilibre s'est établi au profit du pouvoir turc » dans le chaos des propagandes nationalistes grecque, bulgare, serbe et même... roumaine. Ses premières constatations sur l'état de la Macédoine et son avenir sont équivoques. Il est proche de la gauche démocratique française, mais il est aussi un ressortissant de la deuxième puissance coloniale du monde. C'est ce paradoxe qui ressort de ses premières analyses exposées au début de son premier livre intitulé « La Macédoine » où prévaut sa recherche pour définir les conditions de la colonisation. Il décrit les avantages de la situation géographique de la région sur l'axe Morava-Vardar qui relie l'Europe centrale à la mer Égée et son territoire, globalement inchangé depuis Philippe II, roi des Macédoniens de 359 à 336 av. J.-C. Il insiste sur les potentialités naturelles que possède la Macédoine dont pourraient bénéficier les futurs 
colonisateurs. En attendant, il considère que la Macédoine est la propriété de la Turquie.

Quand il revient en 1896, il constate que depuis sa première visite, à cause de l'oppression turque, des razzias albanaises, des ingérences des puissances et des propagandes des nouveaux États sud balkaniques, la situation de la population est devenue insupportable. Et il s'écrie : «que n'importe quel avenir puisse être préféré à l'état présent. La Macédoine aux Serbes! La Macédoine aux Grecs, aux Bulgares, à l'Autriche ou même aux Macédoniens !»

À l'époque, l'ethnicité de la population était définie par les propagandes des prétendants à la possession de la Macédoine. On utilisait le terme de «race" sans critères de définition. C'est la raison pour laquelle Victor Bérard, au début de ses enquêtes, distinguait des « races» de Grecs, Bulgares, Serbes, Valaques (ou Roumains), tout en admettant qu'il y avait aussi des Macédoniens.

Par la suite, plus l'enquête a avancé sur le terrain, moins il a fait ces distinctions, et pour dans son deuxième livre (Pro Macedonia) il affirme que la Macédoine est habitée par des Macédoniens et ceci malgré l'endoctrinement des populations par les propagandes étrangères.

D'ailleurs, l'année où Victor Bérard publie à Paris les résultats de ses enquêtes en Macédoine, William Gladstone (1809-1898), ancien Premier ministre britannique, écrivait:» Pourquoi la Macédoine ne serait-elle pas aux Macédoniens comme la Bulgarie aux Bulgares et la Serbie aux Serbes?» Victor Bérard dit la même chose quand, à la fin de ses enquêtes, il écrit qu'il faut laisser "la Macédoine aux Macédoniens ». Les révolutionnaires macédoniens lui ont dit qu'ils organiseraient leur futur État en fédération ou confédération.

Cette idée de fédéralisme et de respect du droit de tous les peuples sans distinction d'appartenance ethnique, de langue ou de religion, était le fondement de l'idéologie socialiste de la fin du XIX ${ }^{e}$ siècle à laquelle Victor Bérard adhérait. Elle était aussi à la base du projet des révolutionnaires macédoniens qu'il connaissait. Le projet fédéraliste pour la Macédoine avait été publié en France dans la Revue socialiste, en 1895, sous le titre «le Fédéralisme et la question d'Orient ", puis, repris en 1896 dans la revue "Question sociale " par P. Argyriadès et P. Lagarde sous le titre "Solution de la question d'Orient-la Confédération balkanique et la Macédoine ». Bien qu'il ait pu être considéré à l'époque comme utopique (et d'ailleurs même dans les circonstances balkaniques actuelles ...) ce projet est pourtant celui qui cherche une solution à partir de la réalité intérieure macédonienne.

Argyriadès était persuadé que la confédération, comme forme de gouvernement, s'imposait parce que la Macédoine était le "portrait en miniature de la péninsule balkanique par la variété des populations qui y habitent». Il pensait que ceci pouvait être considéré comme un obstacle momentané, mais qu'il fallait rechercher «l'unité dans la variété » et "l'autonomie dans la solidarité »... mais, écrivait-il, « heureusement, un parti national macédonien s'est constitué depuis quelque temps »... Il s'agissait de la création en 1893, à Salonique, de l'Organisation révolutionnaire intérieure macédonienne (ORIM) et de son Congrès en 1896, toujours à Salonique. Avocat à la Cour d'appel de Paris, directeur de la revue "la Question sociale», et président de la Ligue de la Conférence balkanique ", Argyriadès exprimait exactement l'idéologie de l'ORIM ; il faisait une nette distinction entre Grecs et Macédoniens, avec un soupçon de nationalisme macédonien quand il écrivait « le paysan macédonien n’a 
rien de la vantardise et de la légèreté du paysan hellène » et s'écriait : «Est-ce que la Macédoine, cette patrie des deux plus hautes personnalités du monde antique, Aristote et Alexandre le Grand, ne devrait pas - elle qui a conquis le monde - reconquérir son indépendance et son autonomie?» Puis, se rappelant que la Russie «s'apprêtait à transformer la Bulgarie en province russe » en englobant la Macédoine, il écrivait que «les Macédoniens ne veulent pas de ces caresses qui peuvent les étouffer. Ils veulent rester Macédoniens sans autre épithète ».

«Les petits États grec, bulgare et serbe se disputent la possession de la Macédoine, se prévalent de toutes espèces de raisons chauvines et historiques, inventées à l'appui de leurs intérêts, ne s'apercevant pas que s'il fallait se baser sur les raisons historiques, c'est plutôt la Macédoine qui serait en droit de posséder toutes les contrées qui veulent son absorption, car c'est elle seule qui les a autrefois conquises et possédées".

Après la publication de son projet, Argyriades reçut des lettres d'approbation d'un grand nombre d'intellectuels, d'abord de France, puis de Londres, de Bucarest, de Barcelone, de Copenhague, de Berne, de Milan, de Lausanne ainsi que d'autres centres intellectuels en Europe.

Tel était l'état d'esprit des intellectuels de gauche à Paris au moment où Victor Bérard a commencé ses enquêtes en Macédoine.

"Le découpage administratif de la Macédoine fin XIXe siècle »

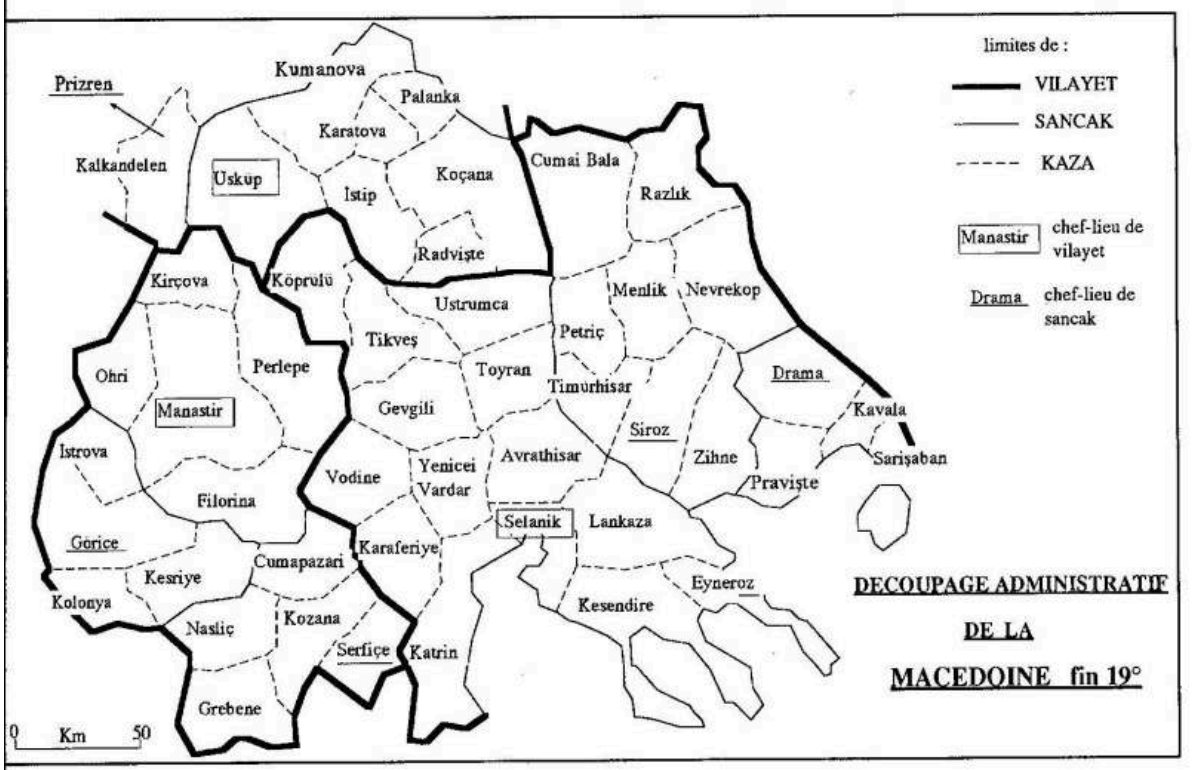

in «La population de la Macédoine au XIXe siècle » Daniel Panzac, Revue du Monde musulman et de la Méditerranée nº 66 (1992/4) consacrée aux « Balkans à l'époque ottomane »

\section{Les enquêtes de Victor Bérard}

Dans ce contexte sud balkanique complexe Victor Bérard a tenté de comprendre la situation exacte en Macédoine. Il s'intéressait comme Paul Vidal de la Blache, le fondateur de la géographie humaine en France, qui était son ami, à tous les aspects d'un pays. Dans ses enquêtes, il décrivit la géographie, le cadre et le mode de vie des 
habitants et même, par leurs vêtements, il identifia leur origine apparente et leur religion. Quant au critère de langue, il formula des réserves, car, " la question même des langues est secondaire, écrivit-il, par exemple, on rencontre des sentiments helléniques ou bulgares chez des paysans qui ne parlent guère que le turc [...] la Macédoine travaillée et retournée par les propagandes n'est pas divisée en peuples rivaux, mais en partis hostiles, et la carte des nationalités ne correspond que très mal à la carte de ces partis $»^{4}$.

Quand il a visité Pristina et Skopje, il a indiqué que la frontière occidentale de la Macédoine était la chaîne de hautes montagnes qui s'étend du Pinde et de la Vistrica (Bistrica en slave, Haliacmon en grec) au Sud jusqu'au Šar-Dagh (la montagne Char en turc). Sa frontière septentrionale part de cette montagne et à travers le Kara-Dagh (la Montagne noire, Skopska Cerna Gora en macédonien) et Orbelia va jusqu'aux sources du Strymon. Elle sépare la Macédoine de la Dardanie, l'actuel Kosovo. Pour la frontière méridionale, il indiqua le « Roumlouk» le territoire habité par les Valaques autour de Metsovo.

La Macédoine faisait partie de l'élayet de la Roumélie (c'est à dire des Balkans de l'Empire romain d'Orient), province qui, en 1865, a été partagée en cinq vilayets. Cette réforme administrative a divisé la Macédoine en trois vilayets, Selanik (Salonique), Monastir (Bitola) et une partie du Nord de la Macédoine incluse dans le vilayet du Kosovo, (chef-lieu Priština).

Quand Victor Bérard arriva en Macédoine, en octobre 1896, la Macédoine, et particulièrement Skopje, était submergée par les Muhadjirs, les musulmans de toutes origines chassés des nouveaux États sud balkaniques. "Ils augmentent les forces et le zèle de l'Islam macédonien ", écrivit-il. Il commença son enquête en Macédoine par Skopje et Pristina dans le vilayet du Kosovo. Il consacra aux Albanais une étude sur leurs mœurs très particulières et leurs rapports surtout avec les Serbes.

Il apprit que, pour satisfaire les Albanais du Kosovo qui avaient chassé le consul français de Pristina, tué le consul serbe et en même temps déposé une plainte auprès du sultan en se présentant comme des victimes, le sultan leur avait donné raison, tout en déplaçant le chef-lieu du vilayet du Kosovo de Pristina à Uskub (Skopje). C'est ainsi que Skopje devint le centre administratif du vilayet du Kosovo bien qu'à l'époque, il y eut très peu d'Albanais dans cette ville; dans son décompte des nationalités, Bérard ne mentionnait même pas leur présence.

Lors de sa première visite de Skopje en 1890 et à partir de ce qu'il avait vu, il avait conclu que les Macédoniens, soumis aux propagandes grecque, bulgare et serbe, préféraient le servage turc aux pouvoirs des États sud balkaniques nouvellement créés par les puissances. Mais en 1896, il constata qu'il y avait eu un grand changement, que les conditions s'étaient aggravées et que les trois prétendants à la possession de la Macédoine étaient beaucoup plus virulents. Avec leurs églises et leurs écoles, ils étaient en train de conditionner les Macédoniens et de les transformer en Grecs, Bulgares ou Serbes, tandis que ceux qui tiraient les ficelles se trouvaient à Vienne, SaintPétersbourg, Londres, Paris et Istanbul.

Il écrivit à Salonique: "Quand la Macédoine existait par elle-même, quand les rois indigènes possédaient cette contrée, leur capitale, Pella, n'était pas en cet endroit, mais de l'autre côté du Vardar, au pied des monts de l'Ouest, à l'entrée des défilés qui conduisent vers les plateaux, vers les lacs et vers les plaines de l'intérieur ». Ce rappel 
très succinct s'adressait a priori à des lecteurs qui connaissaient l'histoire ancienne de la région et Bérard n'approfondit pas la problématique du passé. C'est Gaston Routier, dans son livre "La Question macédonienne $»^{5}$, le témoin de l'insurrection d'Ilinden du 2 août 1903, qui tenta de relier les événements historiques. Plongé dans les guerres de propagande de ceux qui revendiquaient la Macédoine, il se rendit compte que la problématique macédonienne avait des racines plus profondes que ce qu'il avait entendu sur place de la part des tenants des idéologies nationalistes. Pour cette raison, de retour à Paris, il compléta son étude par un chapitre introductif dans lequel il retraça l'histoire de la Macédoine depuis Alexandre le Grand, les invasions des peuples barbares pendant l'Empire romain d'Orient et jusqu'à l'insurrection de 1903. Sa principale conclusion fut : « le partage est impossible » et « il faut laisser la Macédoine aux Macédoniens ».

\section{L'enquête de Victor Bérard à Salonique}

Dans ce contexte de surenchère des propagandes nationalistes de leurs voisins, les Macédoniens créèrent en 1893 à Salonique l'Organisation révolutionnaire intérieure macédonienne (ORIM). Dans la ligne idéologique de l'insurrection macédonienne de Kresna en 1878, l'objectif initial de l'ORIM était l'autonomie avec application des réformes prévues par l'article 23 du Traité de Berlin. Mais au Congrès de l'ORIM de 1896 à Salonique, l'année où Victor Bérard arriva dans cette ville, les révolutionnaires macédoniens décidèrent que l'indépendance devait être obtenue par la révolution. En voyant que la Bulgarie avait annexé de force la Roumélie orientale autonome, les Macédoniens refusèrent de s'associer aux Bulgares pour ne pas connaître le même sort. La réponse des Bulgares à cet acte d'indépendance des Macédoniens fut la création à Sofia en 1895 d'un comité appelé « macédonien » sous contrôle du pouvoir bulgare.

Victor Bérard écrit à propos de Salonique : la ville «n'est pas turque : un tiers au plus de sa population est musulmane et la moitié de ces musulmans encore, se souviennent de leur origine grecque, albanaise ou juive [...]. Les Grecs disent : Salonique est grecque ; les trente mille Grecs de Salonique ne forment qu'un cinquième environ de la population [...]. Salonique n'est pas grecque, ni serbe ni bulgare quoique puissent prétendre Bulgares, Serbes et Grecs. À vrai dire, Salonique n'est même pas une ville macédonienne. Par sa situation, par sa population, elle ne tient presque pas à la Macédoine : elle ne fait pas corps avec le reste du pays [...] ». Et il poursuit : «Salonique est juive [...] ils sont aujourd'hui près de soixante-dix mille. Encore dans ce nombre ne sont pas compris une dizaine de milliers, pour le moins, de juifs authentiques, mais convertis à l'Islam ».

À Salonique, Bérard analysa les rapports de force entre ceux qui revendiquaient la Macédoine. Il écrivit: "chacun sait qu'Athènes, depuis trois ans, est aux mains de l'Angleterre et que Sofia et Belgrade, au contraire, reçoivent le mot de SaintPétersbourg ». Comme il constatait des attaques de l'extérieur des Grecs, des Bulgares et des Serbes sur la population macédonienne, pour la nommer, il utilisa l'expression "population indigène ». En analysant le contenu des propagandes, il observa: "les Bulgares se présentent aux Slaves de Macédoine comme les libérateurs et les éducateurs, ils apportent du dehors le progrès et la lumière, mais imposent aussi leur langue, leur littérature, leur façon d'être et de penser; ils veulent annexer la Macédoine, la conquérir pour le compte de Sofia ». Quant aux Serbes, ils « se présentent 
plutôt comme des frères aînés qui donnent des conseils non des ordres et des exemples plutôt qu'une règle et un canon. Ils proclament le patois macédonien, dialecte serbe [...] ils recueillent les chansons macédoniennes et, sous l'étiquette de chansons serbes, les font apprendre dans leurs écoles (...) Bref, ils se posent en représentants et non en conquérants de la Macédoine. »

\section{L'enquête de Victor Bérard à Monastir-Bitola}

À la fin du XIXe siècle, les Valaques représentaient un facteur important dans la vie politico-religieuse en Macédoine, surtout à Bitola. Ils étaient d'abord favorables au maintien de l'Empire ottoman et se positionnaient du côté des Grecs en tant que patriarchistes. Puis ils ont cherché à nouer des liens avec la Roumanie. Finalement, une grande partie des Valaques de la Macédoine septentrionale a participé aux soulèvements contre les Turcs avec les Macédoniens slavophones dans l'éphémère, mais historiquement fondamentale, République de Kruševo en 1903.

Victor Bérard a trouvé qu'à Bitola toutes les ethnies (qu'il appelle « nations ») « sont en proie aux querelles intestines». Il écrivit qu'à part les Turcs, «il y a des "Slaves bulgarisants », des Valaques hellénisés qui se disent "Grecs » et enfin des Juifs ». Et parmi les hellénisants, «les Grecs de race grecque sont une infime minorité ». Selon son enquête, la propagande bulgare $a$, en ce moment, un grand succès dans le vilayet de Monastir. Mais, écrit-il, «à part les Serbes, les Bulgares ont un autre ennemi, plus puissant et plus pressant aussi : la propagande bulgare est menacée par une révolte de cette Macédoine qu'elle achève à peine de soumettre ». « Parmi les Slaves macédoniens qu'elle vient d'arracher à l'hellénisme, plus d'un commence à rêver d'un plus complet affranchissement et voudrait chasser du pays Serbes et Bulgares et Grecs et Valaques pour rendre la Macédoine aux Macédoniens ».

Déjà après l'annexion par les Bulgares de la Roumélie orientale en 1885, les Macédoniens ont été amenés, selon Bérard, «à de nouvelles conceptions patriotiques " et il les exposait ainsi :

"Ils veulent une Macédoine macédonienne, une Macédoine aux Macédoniens, une province privilégiée, autonome ou indépendante, avec un gouvernement quel qu'il soit, pourvu qu'il soit entre leurs mains. Ce gouvernement, disent-ils, élu par les communautés, ne se mêlerait plus à la guerre des races, respecterait toutes les églises et tous les enseignements et, pour ne favoriser ni le grec, ni le bulgare, ni le valaque, emprunterait au besoin sa langue officielle aux diplomates et adopterait le français [...] Leur capitale, Monastir ou Salonique, à moitié chemin d'Athènes, de Sofia et de Belgrade, à la rencontre de l'hellénisme et de la Slavie, pourrait même devenir le trait d'union - qui sait - le centre de la fédération future "

41 Ici Victor Bérard est passé du scepticisme du début de son enquête à une acceptation presque totale des revendications des Macédoniens.

\section{La Macédoine au Moyen Âge selon Victor Bérard}

Dans son livre «La Macédoine " (déjà cité), il a livré une information qui mériterait d'être vérifiée. Il a écrit qu'à côté de Bitola et de l'antique Héracléa, fondée par le roi macédonien Philippe II, « un Empire slavo-valaque avait jadis existé en Macédoine vers le $\mathrm{XI}^{\mathrm{e}}$ siècle, autour du pays de Prespa qui en était le centre, sous des chefs valaques d'origine danubienne »... Cette information intrigue les historiens parce que Victor 
Bérard a été le seul à suggérer qu'il y aurait eu des Valaques dans la constitution de l'État de Samuel.

Le pays qu'il désignait correspond au noyau central de l'Empire de Samuel qui a existé entre 976 et 1018. À cause du surnom donné à l'empereur byzantin Basile II, «bulgarochtone» le vainqueur de Samuel, son empire a été considéré comme «bulgare ». Jean-Claude Cheynet ${ }^{6}$ dans « Byzance. L'Empire romain d'Orient " écrit au sujet de Basile II : «le surnom de «tueur de Bulgares» (Bulgarochtone) sous lequel il est passé à la postérité ne paraît pas dans les sources avant la fin du XII e siècle ». Donc presque deux siècles après la bataille de Struma en 1014 quand il écrasa l'armée de Samuel. Et grâce à ce subterfuge, grec ou bulgare, l'historiographie a classé Samuel parmi les khans ou tsars bulgares, et son État, qui était constitué par le peuple autochtone, était appelé « Bulgarie ».

"Une explication de cette méprise a été donnée par le byzantologue français Alain Ducellier. Dans le paragraphe "l'œuvre des grands usurpateurs" Phocas (963-969) fit appel aux Russes, les incitant à occuper la Bulgarie. Le prince russe Svjatoslav soumit rapidement la fragile Bulgarie et déposa Boris, fils et successeur de Pierre... " Puis les Byzantins chassent les Russes et occupent la Bulgarie proprement dite. Ducellier poursuit: "l'État bulgare ne fut pas reconstitué et les fils de Pierre, Boris et Romain, furent pris en otages et conduits à Constantinople »... Selon lui, «en 971, les Byzantins n'avaient probablement soumis que la région orientale du royaume bulgare » et "un soulèvement éclata en effet dans la partie occidentale contre les Bulgares » (c'est-à-dire en Macédoine). Le soulèvement a commencé, "vraisemblablement [...] en 976, après la mort de Jean Tzimiskès [...] Le type d'État issu du soulèvement de 976 est un point plus important et tout aussi discuté."

L'origine de Samuel, selon Bérard, serait valaque et, selon Ducellier, arménienne, mais les autres historiens ne soutiennent pas ces hypothèses. On suppose que sa mère aurait pu être d'origine arménienne, issue de la population transférée en Macédoine par les Byzantins, mais on affirme que son père appartenait à une tribu macédonienne ancienne. Cependant ce qui est indiscutable, c'est que l'État de Samuel était constitué par un pouvoir autochtone en Macédoine, sans rapport avec la Bulgarie.

Cependant, il est possible que Bérard ait connu la théorie selon laquelle les Valaques de la Macédoine historique et géographique seraient des descendants des Macédoniens antiques qui auraient adopté les rudiments de la langue latine, de même qu'une partie des Daces (dans l'actuelle Roumanie) pendant l'occupation romaine. Si cette information était confirmée, les Valaques dont il est question, seraient donc des Macédoniens latinisés, mais sans rapport avec la Valachie.

\section{La dernière ville de Macédoine que Victor Bérard ait visitée est Serrès}

En visitant Serrès, le jugement de Victor Bérard est net :

"c'est une terre grecque, entièrement grecque ", mais il remarque que la population vers la Struma est slave. D'autre part, selon lui, «les petites villes de Koukouche et de Doiran sont exclusivement slaves». (Aujourd'hui, Koukouche a été rebaptisée par les Grecs Kilkis). Il observe que les Grecs sont installés dans la Chalcidique "mais de ce côté, la Slavie descend encore jusqu'aux murailles de Salonique». Enfin, il rappelle la limite orientale de la Macédoine : «le Rhodope borde ici la Macédoine ». 


\section{Les bombes de Salonique et l'insurrection macédonienne de la Saint-Élie}

En 1901, Victor Bérard devient chroniqueur pour les questions extérieures à la Revue de Paris. En 1902-1903, il revient à l'Antiquité et publie un livre "Les Phéniciens et l'Odyssée ", puis, en 1904, il devient le secrétaire général de la Revue de Paris. C'est de retour de Macédoine qu'il publie dans cette revue, en juin 1903, une importante étude sur les événements survenus en Macédoine. Il reprendra une partie de cette étude dans son livre « Pro Macedonia».

Déjà, en 1897, il avait constaté la dégradation des conditions de vie de la population en Macédoine. Il expliquait à l'époque qu'elle était exploitée par les Turcs et le clergé grec en écrivant : « de concert également intéressés à garder cette Macédoine, le Sultan et le Patriarche travaillaient et parvenaient sans peine à la maintenir dans l'ignorance ». En même temps, cette population était soumise aux propagandes grecque, bulgare et serbe. Il critiquait les prétentions démesurées des Grecs qui, selon lui, «s'imaginent (c'est ce qu'ils lisent dans Hérodote) que, seuls, ils peuvent être le boulevard de l'Europe contre l'Asie. » D'autre part, il a remarqué que "pour les Grecs, le Macédonien n'est toujours... qu'un Barbare ». Ici, Bérard tentait de relier des réminiscences sur les rapports entre les Hellènes et les Macédoniens de l'Antiquité à la situation contemporaine entre les Grecs et les Macédoniens.

À propos des bombes de Salonique, Bérard rappelle que depuis longtemps, les Macédoniens attendent la réalisation des réformes promises par les Turcs et les puissances européennes. Mais il a appris par l'ambassadeur de Russie que, de décembre 1902 à février 1903, les persécutions et les violences ont redoublé. Et il note que « les exactions, brutalités et pillages » sont confirmés aussi par le chargé d'affaires français. À ce propos, il écrit : « l'Europe abandonne la Macédoine aux fureurs maniaques d'Abdul-Hamid. Les puissances européennes déclarent aux Macédoniens aujourd'hui qu'il faut rester sous le couteau, que le sultan est leur maître légitime, absolu, et que l'obéissance à toutes ses folies est le premier de leurs devoirs [...]. C'est alors qu'éclatent les bombes de Salonique (30 avril 1903). » Il signale que « les Comités protestent et que l'Organisation intérieure n'approuve pas ces actes de quelques désespérés ». Il n'approuve pas non plus la violence, mais écrit qu'il réserve son «indignation aux auteurs véritables, à ceux qui, depuis cinquante ans, poussèrent les Macédoniens vers cette impasse ». Et il ajoute : "leur crime est peut-être inexpiable : leur courage fut sûrement héroïque ». Dans sa description des groupes ethniques, en 1903-1904, il n'utilise plus les noms de Bulgares, Serbes ou Slaves pour les insurgés, il les nomme seulement Macédoniens. Il a obtenu des explications sur les rapports des Grecs et des Turcs. Les Macédoniens lui ont dit que «les Grecs aveuglés par leur propagande nationale se sont fait les auxiliaires des Turcs, que le gouvernement d'Athènes s'est fait le bras droit d'Abd-ul-Hamid et que systématiquement, il a organisé et payé la délation contre nous. » Victor Bérard écrit sur ce point "les rapports consulaires de notre dernier Livre jaune (de la diplomatie française) les déclarations et les actes même du gouvernement grec montrent que les Comités disent vrai ». Il a lu aussi dans le journal Le Temps du 5 juin 1903, l'information selon laquelle les Grecs ont livré à la police turque de Salonique trente "Comitadjis ». Il relève également d'autres informations par exemple: «les étudiants d'Athènes adressent au sultan leurs félicitations les plus humbles. Des officiers grecs sont allés rejoindre cette armée turque... » Et de conclure : 
« il est malheureusement vrai que les directeurs de l'hellénisme l'ont engagé dans une voie qui ne peut le mener qu'à la honte.»

L'lllustration no 3131 du 28 septembre 1903

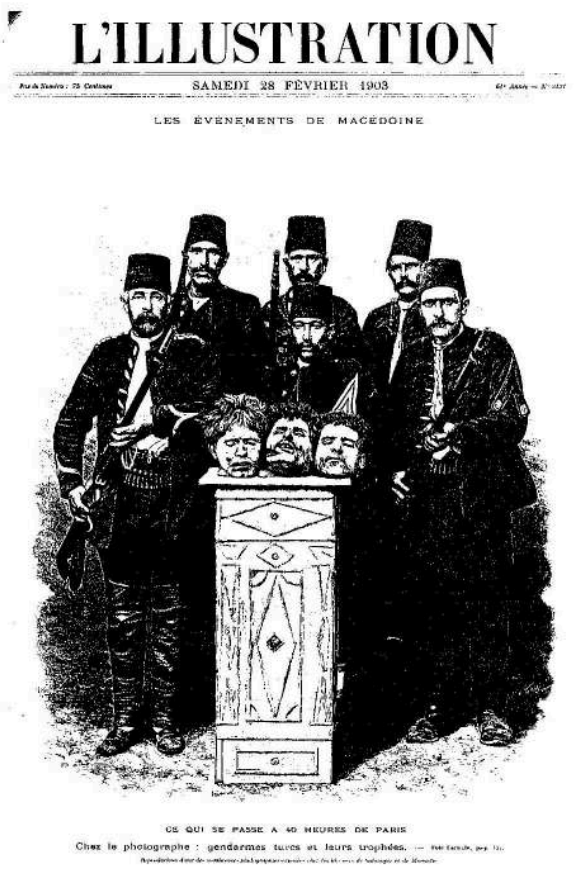

La légende de la page de garde : «Ce qui se passe à 40 heures de Paris ». - «Chez le photographe gendarmes turcs et leurs trophées «. - " L'une des nombreuses photographies exposées chez les libraires de Salonique et de Monastir » écrit Robert Malet, qui raconte dans son article les atrocités commises par les Turcs et les Albanais en Macédoine.

\section{L'insurrection de la Saint-Élie (llinden) 2 août 1903 et les Bulgares}

Les Bulgares qui ont leurs espions en Macédoine suivent les préparatifs pour l'insurrection et quand elle éclate, d'abord dans le vilayet de Monastir-Bitola, ils stoppent leur armée à la frontière de la Macédoine sans intervenir. Puis, une fois finis les «pillages, les meurtres, les déportations avec la complicité grecque dans son étouffement, » écrit Bérard, les Bulgares adressent un mémorandum aux chancelleries le 10 août 1903. Ils y ont énuméré en détail toutes les exactions des Turcs en Macédoine. Bien que les Bulgares n'aient pas participé à l'insurrection, ils soutiennent contre toute évidence historique que la République de Kruševo, proclamée pendant l'insurrection, serait leur œuvre. Cependant, la dernière phrase de ce mémorandum montre clairement, de l'aveu même des Bulgares, qu'ils sont étrangers au mouvement insurrectionnel en Macédoine: "Les causes de cette révolution sont aujourd'hui connues et les responsabilités d'ores et déjà établies : la Sublime Porte ne pourra plus en accuser la Principauté. » (bulgare), Sofia, le 28 juillet (10 août) 1903. Mais ce fait historique n'a pas empêché leurs historiens d'essayer de le bulgariser ainsi que la République de Kruševo qui représente le fondement historique de l'État contemporain de la Macédoine. 


\section{L'idée macédonienne de Victor Bérard}

51 En reprenant certaines parties de son étude publiée dans la Revue de Paris en juin 1903 et dans son livre "Pro Macedonia », dont le texte, achevé le 15 décembre 1903, a été publié en 1904, où il expose son idée sur la Macédoine et le programme des révolutionnaires macédoniens, on lit :

" Elle est là, cette idée macédonienne, dont les Grecs s'entêtent à nier l'existence et dont ils feraient mieux de mesurer la grandeur et les chances d'avenir! Car cette idée macédonienne porte peut-être en elle des germes que, serbe, bulgare ou grecque, les autres idées balkaniques n'avaient et n'ont pas. Serbe, bulgare ou grecque, ces idées jusqu'ici n'ont été que nationalistes: elles ne visent qu'au renversement de l'oppression étrangère; elles ne rêvent que l'extension indéfinie des frontières nationales aux dépens de la turquerie ou des chrétientés voisines. Le Grec, en particulier, se figure que le monde sera régénéré, pacifié, heureux, à la minute où la croix hellénique sur fond bleu remplacera le croissant turc sur fond rouge."

Puis Victor Bérard présente le programme des Macédoniens :

"Les Macédoniens ont des visées plus hautes, des soucis plus lointains. Les ambitions d'une petite patrie et l'égoïsme d'une petite race ne leur semblent pas le but idéal. Changer l'oppression turque contre la dépendance grecque, serbe ou bulgare ne leur semble pas un gain suffisant".

Sur l'avenir de la Macédoine, Bérard expose leurs idées sur une «fédération balkanique »:

"Ils veulent qu'elle ne devienne pas la conquête exclusive et la victime d'aucune race particulière, mais que tous les peuples y puissent coexister. Ils se proclament donc fédéralistes. Ils demandent à leurs adeptes que chacun dépose son égoisme national et travaille d'abord au développement de la communauté macédonienne pour préparer l'établissement de la Fédération balkanique ".

53 Mais, connaissant la géopolitique de son temps et le règne des forces souterraines dans les Balkans du Sud, il conclut avec lucidité :

"Ce sont-là, peut-être, ambitions chimériques, mais ce sont aussi ambitions nouvelles au Levant. Ni le Grec, ni le Bulgare ne les avaient formulées. Le Grec surtout est si peu fait à les comprendre, qu'il est tout prêt à les nier.».

54 Cependant, il continue à croire à la sincérité des auteurs de ce programme. Pour cette raison, il écrit : « Il ne faut donc pas mettre en doute la bonne foi des Comités quand, ni Bulgares, ni Serbes, ni Grecs, mais Macédoniens, ils proclament leur détachement absolu de toute petite patrie ", et il conclut, "telle est assurément leur conception directrice et, d'ailleurs, tel est leur véritable intérêt : à la remorque des Grecs ou des Bulgares, les Macédoniens ne seraient pas grand-chose; à la tête des peuples balkaniques, ils peuvent avoir un rôle de premier plan». Les révolutionnaires macédoniens lui ont expliqué que pour son organisation future, la Macédoine prendrait l'exemple de la Suisse... « Il ne faut donc pas les accuser de chimère : ils ont un modèle précis devant les yeux [...], ils savent qu'entre les misères du présent et le triomphe de ce lointain idéal la route sera longue, très longue, que des générations, des siècles peutêtre s'useront à cette tâche et que, seule, une méthodique et invincible patience conduira quelques jours leurs peuples à ce règne de la fraternité ». 


\section{Les visions historiques et géopolitiques à long terme de Victor Bérard}

Il faut souligner que la contribution de Victor Bérard dans l'analyse du processus du «tronçonnage" (le terme est de Jacques Ancel) de la Macédoine est d'autant plus important qu'il n'était pas un simple enquêteur, mais un spécialiste de l'Antiquité des Grecs et des Macédoniens quand, à la fin du XIX ${ }^{e}$ siècle, il analyse leurs comportements par rapport à l'avenir de la Macédoine. Par conséquent, on ne peut dissocier l'enquêteur du spécialiste de l'Antiquité et ne pas voir transparaître dans son opinion concernant les idéologies nationales des Grecs et des Macédoniens du XIX ${ }^{\mathrm{e}}$ siècle, ce qu'il sait de l'histoire antique. Cette citation le confirme :

«De même que la Macédoine ancienne fit l'union de tous le Grec contre le patriotisme des petites cités, de même la Macédoine future fera l'union de tous les chrétiens contre le patriotisme des petits États... À la suite de Philippe et d'Alexandre, les Macédoniens recommencent, en rêve, la conquête du monde levantin.»

\section{Le contentieux de Victor Bérard avec les Grecs sur la question macédonienne}

Connaisseur des Grecs antiques et modernes, Victor Bérard fait une différence entre le peuple et ses politiciens qu'il accuse "d'ignorance et d'égoïsme ». Pour illustrer son propos, il expose ici le comportement de l'un d'eux (le recteur de l'Université d'Athènes) qui nie la réalité macédonienne.

Se considérant comme ami sincère des Grecs, Bérard montre dans ce récit une grande déception :

«Aux Hellènes

Envoyé à Paris pour défendre les droits de l'hellénisme, M. Kasasis, recteur de l'Université d'Athènes, proteste contre certaines de mes affirmations, j'ai, paraitt-il, "répété des faits inexacts,- car il n'est pas vrai que les étudiants d'Athènes aient envoyé au Sultan des félicitations quelconques, et est complètement faux que des officiers grecs aient mis leur épée au service de la Porte"...

Kasasis me demande de lui "indiquer les chefs du mouvement dit macédonien qui résident en Macédoine". Il déclare que jamais la Grèce n'a "conclut une alliance avec la Turquie"; il me demande "en quoi consiste en fait cette fameuse alliance", et il en appelle "encore à ma bonne foi, qui a été sans doute surprise, et à la conscience du monde civilisé ».

En même temps qu'il déposait une lettre à la Revue de Paris, M. Kasasis voulait bien, par deux fois, me rendre visite et m'expliquer le douloureux étonnement causé à tous les Hellènes par les articles «d'un homme dont le philhellénisme, disait-il, n'a jamais été mis en doute ». Il me demandait de prendre part au meeting franco-grec, qui devait se réunir sous la présidence de M. Henri Houssaye. Je le priai instamment de me donner la parole pour me permettre d'exposer mes raisons et mes regrets, car ce n'est pas sans de profonds regrets vous le savez bien - que l'on doit à certaines heures tenir certain langage à ses plus chers amis. J'indiquai d'avance à $M$. Kasasis ce que je voulais dire : il refusa de m'inscrire parmi les orateurs.

Puisque je n'ai pas pu me faire entendre des Hellènes de Paris, je m'adresse à vous, mes chers amis de la Grèce libre et irrédimée ${ }^{7}$. Rentrant de Macédoine, il y a près de sept ans, je vous exposais déjà, à la fin de mon livre sur la Macédoine, le dommage toujours grandissant que causent à l'Idée l'ignorance et l'égoïsme des politiciens d'Athènes. Je vous montrais l'hellénisme macédonien exploité, persécuté, trahi par ces gens qui ne voient dans l'Idée que source de discours ou de bénéfices.

Mesurez aujourd'hui ce qu'ils ont fait de la Macédoine. Écoutez la clameur d'indignation 
qu'en France, en Angleterre, en Italie, chez toutes les nations civilisées, chez tous les peuples vos amis, leur conduite a soulevé contre eux, contre vous, et, puisqu'ils me forcent de donner au public la preuve de leurs agissements, ne rejetez que sur eux les conséquences de cette polémique.»

\section{L'actualité des études macédoniennes de Victor Bérard} caractéristiques à contre-courant des nationalismes étroits des petits peuples sud balkaniques patronnés par les grandes puissances. Et parce que leurs descendants ont suivi leur exemple, dans une configuration géopolitique fondamentalement identique, 
ce qui reste encore de la Macédoine historique et géographique risque aujourd'hui de disparaître définitivement.

\section{NOTES}

1. Ses ouvrages principaux sur la Macédoine :

Victor Bérard, La Turquie et l'hellénisme contemporain: Macédoine, Hellènes, Bulgares, Valaques, Paris, Félix Alcan, 1893.

Victor Bérard, La Macédoine, Paris, Calmann-Levy, 1897.

Victor Bérard, Pro Macedonia : l'action austro-russe, les bombes de Salonique, le mémorandum bulgare, une action franco-anglo-italienne, aux Hellènes, Paris, A. Colin, 1904.

2. Thierry Mudry. Guerre de religions dans les Balkans. Paris, Ellipses, 2005.

3. Jacques Ancel, Manuel historique de la Question d'Orient (1792-1925). Paris, Delagrave, 1926.

4. À ce propos Ernest Weibel cite H. N. Brailsford (Macedonia. Its races and their future, London, 1906, p.102). Il écrit : « On pouvait rencontrer dans les villages un père de famille grec qui avait des fils dont l'un était Bulgare et l'autre Serbe ou Roumain. »

5. Paris Librairie Le Soudier, 1903.

6. Jean-Claude Cheynet, Byzance. L'Empire romain d'Orient, Paris, A. Colin, 2002, p. 68.

7. Terres jugées «nationales » et pas encore récupérées sur les Turcs. Cette citation est extraite de Pro Macedonia.

8. Versailles, Trimontium, 2003.

\section{RÉSUMÉS}

Un helléniste convaincu, Victor Bérard, en vient, au début du XX $\mathrm{X}^{\mathrm{e}}$ siècle à soutenir l'existence de « Macédoniens » et le slogan « la Macédoine aux Macédoniens".

Le Congrès de Berlin en 1878 avait laissé la Macédoine aux mains des Ottomans. La Grèce, la Serbie et la Bulgarie, parvenues à ses limites et prévoyant le retrait futur des Ottomans peaufinent les arguments linguistiques et historiques qui justifieront leurs revendications territoriales. Victor Bérard, un helléniste respecté et bon connaisseur de la région sud balkanique, effectue des enquêtes en Macédoine en 1896 et 1903 qu'il publie à Paris.

Cette étude montre comment, dans le contexte de la propagande nationaliste des prétendants à la possession de la Macédoine, Victor Bérard en vient progressivement à affirmer qu'il existe une population autochtone, les Macédoniens. Il soutient leur programme pour la constitution d'une fédération ou confédération avec le slogan « la Macédoine aux Macédoniens » ce qui fait toute l'actualité de ses ouvrages.

In 1878, the Congress of Berlin had left Macedonia in the hands of the Ottomans. Greece, Serbia and Bulgaria had reached its limits. Anticipating the Ottoman retreat, they polish language and 
historical arguments that will justify their territorial claims. Victor Bérard, a respected Hellenist and a good expert of the southern Balkans, is doing researches in Macedonia in 1896 and 1903. These will be later published in Paris.

This study shows how, in the context of the nationalist propaganda build-up made by the candidates for the possession of Macedonia, Victor Bérard comes progressively to assert the existence of a native population: the Macedonians. He supports their program for the forming of a federation or confederation which slogan would be "Macedonia to Macedonians". This makes his works very topical.

\section{INDEX}

Thèmes : Histoire

Mots-clés : fédération macédonienne, Berlin (congrès de), identité macédonienne, Comitadji, Exarchat, Millet, propagande nationaliste, ORIM/VRMO, Roumélie orientale, Rum/Roum

Keywords : journeys in Macedonia, macedonian federation, macedonian identity, nationalistic propaganda, Balkans, Greece, Macedonia, Pristina, Skopje, Salonika, Monastir, Serres, Balkan Wars (1912-1913), Congress of Berlin 1878, History

Index chronologique : congrès de Berlin (1978), dix-neuvième siècle, guerres balkaniques

(1912-1913)

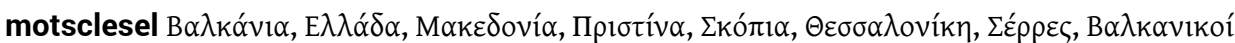

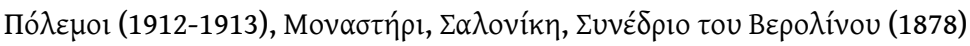

motsclestr Balkanlar, Yunanistan, Makedonya, Pristina, Üsküb, Selanik, Serres, Balkan Savaşları (1912-1913), Berlin Kongresi (1878), Bitola

motsclesmk БАЛКАНОТ, ГРЦИЈА, МАКЕДОНИЈА, ПРИШТИНА, СКОПЈЕ, СОЛУН, БИТОЛА

Index géographique : Balkans, Grèce, Macédoine, Pristina, Skopje, Salonique, Serrès, Monastir

\section{AUTEUR}

\section{IVAN SAVEV}

Chercheur indépendant en histoire 